Check for updates

Cite this: RSC Adv., 2017, 7, 18993

Received 6th January 2017

Accepted 23rd March 2017

DOI: $10.1039 / \mathrm{c} 7 \mathrm{ra00220c}$

rsc.li/rsc-advances

\section{DFT investigation of the reaction mechanism for the guanidine catalysed ring-opening of cyclic carbonates by aromatic and alkyl-amines $\uparrow$}

\author{
M. Alves, ${ }^{a b}$ R. Méreau, \\ B. Grignard, ${ }^{\mathrm{b}}$ C. Detrembleur, (iD ${ }^{\mathrm{b}}$ C. Jérôme (iD ${ }^{\mathrm{b}}$ \\ and T. Tassaing ${ }^{a}$
}

\begin{abstract}
The guanidine catalysed aminolysis of propylene carbonate has been investigated using density functional theory (DFT) and highlights that different reaction pathways are involved, depending on the aromatic or aliphatic nature of the amine. The structural ability of 1,5,7-triazabicyclo[4.4.0]dec-5-ene (TBD) to simultaneously give and receive protons was demonstrated by a detailed mechanistic investigation. The bifunctional activity (base/H-bond donor) of TBD significantly reduces the Gibbs energy of the reaction and allows understanding of its higher efficiency compared to its methyl counterpart (MTBD).
\end{abstract}

\section{Introduction}

In the last few years, developing greener and safer alternatives to the conventional synthesis of polyurethanes (PUs) from isocyanates and polyols has attracted increasing interest to respond to regulation and environmental changes. The most frequently studied and promising route relies on the polyaddition of bis-5-membered cyclic carbonates with diamines, leading to the formation of PolyHydroxyUrethanes (PHUs) ${ }^{1-7}$ that are mainly exploited for coating applications or as crosslinked materials for thermosets or elastomers ${ }^{8-10}$ or as foamed materials. ${ }^{11}$ Besides the improved mechanical and chemical properties of PHUs over conventional PUs, ${ }^{12}$ this chemical pathway also offers the benefit of substituting toxic isocyanates and their phosgene precursors by $\mathrm{CO}_{2}$, an abundant, renewable and environmentally friendly chemical to produce cyclic carbonate precursors entering the synthesis of PHUs. ${ }^{13-18}$ The addition of amines onto cyclic carbonates is governed by several parameters such as the temperature, the nature of the solvent, the solubility, the concentration and the chemical structure of the reactants. In particular, the chemical structure of the amine has a significant impact on the reaction/polymerization rates and yields. ${ }^{19-22}$ Moreover it was shown that aryl amines are less reactive or even non-reactive towards cyclic carbonates compared to the aliphatic ones. Although nucleophilic alkylamines induce ring opening of cyclic carbonates, this

${ }^{a}$ Institut des Sciences Moléculaires, UMR 5255 CNRS Université Bordeaux, 351, Cours de la Libération, F-33405 Talence Cedex, France. E-mail: raphael.mereau@ u-bordeaux.fr; Fax: +33 540006994; Tel: +33540002281

${ }^{b}$ Center for Education and Research on Macromolecules, CESAM Research Unit, Université de Liège, Bâtiment B6a, B-4000 LIEGE, Sart Tilman, Belgium

$\dagger$ Electronic supplementary information (ESI) available. See DOI: $10.1039 / \mathrm{c} 7 \mathrm{ra00220c}$ aminolysis reaction is generally slow and the use of catalysts able to activate the cyclic carbonate is generally required to accelerate the reaction. Many catalysts have been proposed to promote the hydroxyurethane formation at low temperature within short reaction time. ${ }^{\mathbf{1 9 , 2 0 , 2 2 - 2 5}}$ Maisonneuve et $a .^{{ }^{24}}$ screened various catalysts (Schreiner catalyst, LiCl, DBU, ZnAc, MTBD) for a model solvent-free reaction between propylene carbonate and hexylamine. If these catalysts were effective at the early stage of the reaction, they were deactivated after $1 \mathrm{~h}$ with conversions that were similar to those noted for the uncatalysed model reaction. This could be due to the high $\mathrm{H}$ bonds density progressively formed during the conversion in the bulk phase. Blain et al. ${ }^{20}$ carried out a rational investigation of catalytic systems for the aminolysis of model cyclic carbonates by amines in organic solvents. Organocatalysts such as TBD (1,5,7-triazabicyclo[4.4.0]dec-5-ene), phosphines, phosphazenes and cyclohexylphenyl thiourea were found to display a higher efficiency than inorganic Lewis acids $\left(\mathrm{MgBr}_{2}, \mathrm{FeCl}_{3}\right.$, $\left.\mathrm{Fe}(\mathrm{OTf})_{3} \ldots\right)$. The same conclusion was drawn from the investigation of Lambeth et al. ${ }^{19}$ who found TBD as the most potent organocatalyst to fasten the step-growth polymerization of biscyclic carbonates and amines. In addition, PHUs synthesized in the presence of TBD at room temperature showed higher molar mass than the corresponding polymers produced in the absence of catalyst. ${ }^{26}$ However, with or without catalyst, the soproduced PHUs exhibited low molar masses which probably arose from side reactions as recently proposed by Caillol et al. ${ }^{27}$ To explain the higher catalytic efficiency of TBD, the authors proposed that this guanidine derivative could potentially act as a bifunctional nucleophilic catalyst as reported previously in quantum chemical studies for the Ring Opening Polymerization (ROP) of esters, ${ }^{28-31}$ the intramolecular aldol reaction of acyclic ketoaldehyde $\mathrm{e}^{32}$ or the hydrolysis of acetonitrile. ${ }^{33}$ The mechanism of the uncatalysed hydroxyurethane formation by 
aminolysis of carbonate was previously investigated in detail by Zabalov et al. ${ }^{34-36}$ using DFT calculations. They established that the reaction might progress notably throughout a six-centre ring intermediate based on the 5-membered cyclic carbonate and two amine molecules, one playing a catalytic role. Moreover, they highlighted that acetic acid could act as a bifunctional catalyst decreasing the activation energy by concerted protons transfers. ${ }^{37}$ More recently, Kleij et al. ${ }^{22}$ reported that TBD was an effective organocatalyst for the challenging formation of $\mathrm{N}$-aryl carbamates from cyclic carbonates and aromatic amines. In addition, they reported a DFT investigation that evidenced the differences in the TBD mediated mechanisms with aniline and butylamine. Although the catalytic role of TBD as proton donor and acceptor was highlighted, the activation pathway differs from previous DFT calculations studies involving concerted proton transfer. ${ }^{29,32,33}$

In our continuous effort to promote the organocatalytic synthesis of PHUs and to fully understand the origin of the high catalytic activity of TBD organocatalyst, we report a detailed mechanistic study of the guanidine organocatalysed ringopening of propylene carbonate by amines using DFT calculations. In order to highlight the influence of the amine nucleophilicity, the uncatalysed model reaction between propylene carbonate and aniline, methylamine and cyclohexylamine was first considered. Then, the same reactions were reinvestigated using TBD as catalyst and compared with the ones promoted by 7-methyl-TBD (MTBD). For all pathways, detailed structural and energetic information of transition states and intermediates have been optimized. We emphasize that our "gas phase" DFT calculations that consider one molecule of carbonate reacting with one amine molecule is appropriate to model reactions carried out with the reactants diluted in an aprotic organic solvent. For a proper modelling of reactions performed in the bulk, we should have taken into account explicitly in our calculations additional reactant molecules such as two or three amine molecules which is beyond the scope of the paper.

\section{Experimental}

\subsection{Computational details}

Preliminary calculations of equilibrium structures were performed using a semi-empirical model $\left(A M 1-\mathrm{D}_{3} \mathrm{H}_{4}\right)^{38,39}$ to determine the most stable conformations. These semi-empirical calculations were performed using the AMPAC software ${ }^{40}$ Using the same semi-empirical model $\left(\mathrm{AM} 1-\mathrm{D}_{3} \mathrm{H}_{4}\right)$, the CHAIN algorithm $^{41}$ implemented in the AMPAC software was used for locating along the reaction path the conformations that were identified as intermediates and transition states. The lowest energy structures obtained at the AM1- $\mathrm{D}_{3} \mathrm{H}_{4}$ level were further investigated using the Density Functional Theory method (DFT) implemented in the Gaussian 09 package..$^{42}$ DFT calculations of geometries, energies, and vibrational frequencies reported in this paper were carried out with the M06-2X functional ${ }^{43}$ using the 6-311G(d,p) basis set.

All frequencies of each structure have also been calculated to verify the presence of a single imaginary frequency for transition states and the absence of imaginary frequency for ground states. The intrinsic reaction coordinate (IRC) method has been used to verify that the obtained transition states were effectively connected to the desired minima. For all catalysts, a wide range of possible configurations and interactions have been modelled and the more stable of them are reported in this work. To consider entropic effects, the energies mentioned in this study correspond to the Gibbs free energy $(\Delta G)$.

\section{Results and discussion}

The mechanistic study through DFT simulation was realised for a model aminolysis reaction between propylene carbonate (PC) and an amine. Only the most favourable pathway is reported.

\subsection{Cyclic carbonate - amine coupling without catalyst}

A racemic mixture is obtained by aminolysis of the racemic propylene carbonate (Scheme 1). Depending of the regioselectivity of the ring-opening, a primary or a secondary alcohol is synthesized. It can be noted that the aminolysis of propylene carbonate by methylamine leads to 4 regio-isomers: $(R)$ - and (S)-1-methyl-2-hydroxyethyl- $N$-methylcarbamate and $(R)$ - and $(S)$-2-hydroxypropyl- $N$-methylcarbamate. The 4 possible reaction paths exhibit very similar exoenergicity as well as activation Gibbs free energies with maximum deviations of 1 $\mathrm{kcal} \mathrm{mol}^{-1}$ (Fig. S1†). The 4 regio-isomers of hydroxyurethane are "cyclic" due to a $\mathrm{H}$-bond between the alcohol and the $\mathrm{O}$ atom of the carbonyl group. ${ }^{36}$ Thus, the differences in term of barrier heights and reaction's Gibbs free energy are so closed that the choice to consider the reaction leading to only one regio-isomer (i.e. the $\mathrm{S}$ product of the secondary alcohol) appears to be sufficiently representative of the reactivity of the cyclic carbonate with an amine. Schematic potential energy profiles obtained at the M06-2X/6-311G(d,p) level and schematic Lewis structures for the aminolysis of PC by methylamine, aniline and cyclohexylamine are depicted in, Fig. 1. After having fully optimized independently PC methylamine, cyclohexylamine, aniline and the corresponding $S$-hydroxyurethane structures, the overall aminolysis pathway between PC and the amines has been modelled by a one-step mechanism. The initial state corresponds to the sum of the Gibbs free energies of each compound (PC, amine) which is taken as the zero energy. The complexes resulting from the van der Waals interactions and $\mathrm{H}$ bonds (IR0) between the amines and PC have a positive Gibbs free energy, of $0.7 \mathrm{kcal} \mathrm{mol}^{-1}, 1.4 \mathrm{kcal} \mathrm{mol}^{-1}$ and $3.1 \mathrm{kcal} \mathrm{mol}^{-1}$ for methylamine, aniline and cyclohexylamine, respectively. The transition state corresponds to the concerted addition of the amine onto the $\mathrm{C}$ atom of the carbonate group of $\mathrm{PC}$, transfer of the proton of the amine to the adjacent $\mathrm{O}$ atom of the carbonate group and the ring-opening of PC (Fig. 2). The reaction is exothermic and the Gibbs energy of the product depends of the nature of the amine. It can be noted that this mechanism is favoured compared to a 2-step pathway involving a zwitterionic intermediate, ammonium alkoxide, resulting from the addition of the amine and the transfer of its proton to the $\mathrm{O}$ atom of the carbonyl. The Gibbs energy for the uncatalysed aminolysis of PC evolves in the following order 


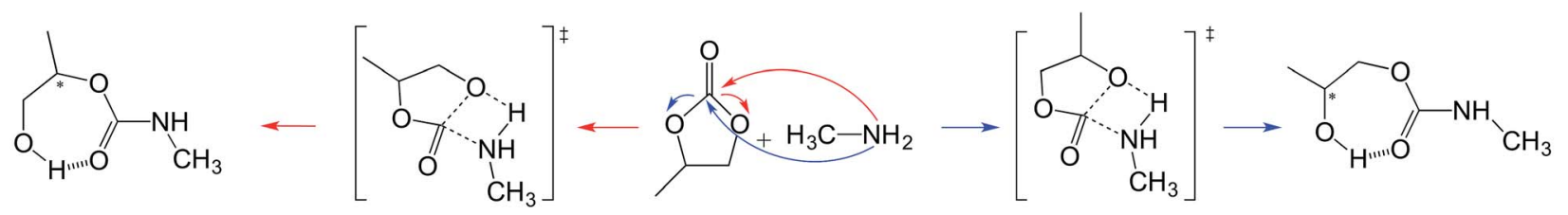

1-methyl-2-hydroxyethyl-N-methylcarbamate

2-hydroxypropyl-N-methylcarbamate

Scheme 1 Racemic aminolysis of propylene carbonate by methylamine.

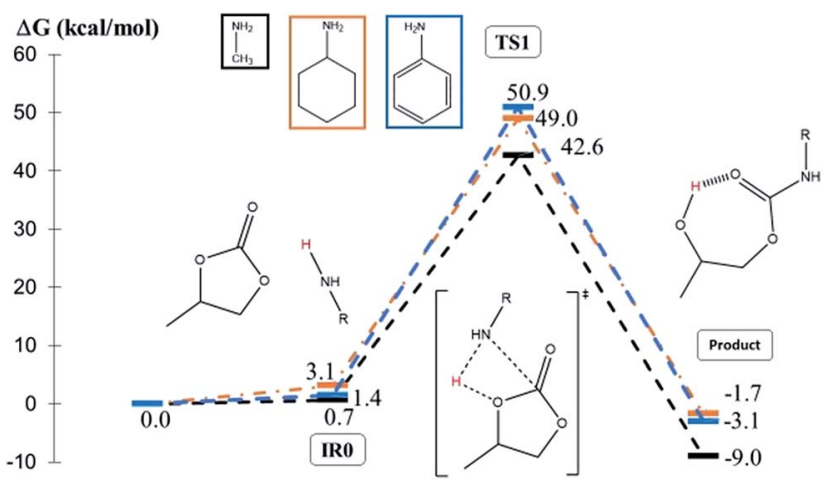

Fig. 1 Free energy profiles (M06-2X/6-311G(d,p)) and Lewis structures for the aminolysis of propylene carbonate by methylamine (black), cyclohexylamine (orange) and aniline (blue) without catalyst.

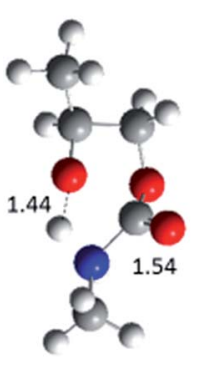

Methylamine

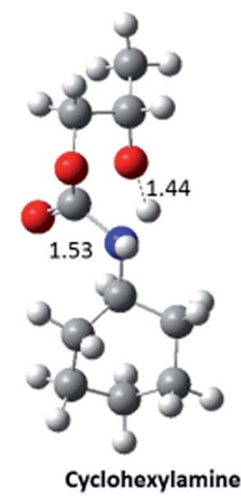

Fig. 2 Optimized geometries of the structures (M06-2X/6-311G(d,p)) of the transition state for the aminolysis of propylene carbonate by methylamine (left), cyclohexylamine (centre) and aniline (right) without catalyst. The intermolecular distances are given in angstrom.

$\Delta G$ (methylamine $)<\Delta G$ (cyclohexylamine $)<\Delta G$ (aniline) . Those results are consistent with previous experimental studies ${ }^{19,20,22}$ reporting that linear alkylamines are more reactive than cyclic amines and aromatic amines. The higher $\Delta G$ value determined for the ring opening of PC by less nucleophilic aniline is related to the lower partial charge on the nitrogen atom of the aromatic amines compared to the aliphatic ones. ${ }^{41}$

As mentioned in the introduction section, the guanidine catalysed coupling of a cyclic carbonate with an amine could follow two different reaction mechanisms where the catalyst plays either the role of a base (activating the amine) or a nucleophile (activating the cyclic carbonate). Preliminary calculations on the reaction of propylene carbonate with methylamine catalysed by TBD clearly discard the nucleophilic mechanism (see ESI $\uparrow$ ). Thus, in the following we will only consider the mechanism where the catalyst acts as a base.

\subsection{Cyclic carbonate - aniline coupling with TBD and MTBD catalyst}

The mechanism of the TBD catalysed aminolysis of propylene carbonate by aniline was investigated at the M06-2X/6$311 \mathrm{G}(\mathrm{d}, \mathrm{p})$ level. The activation mechanism by TBD answers a two-step pathway (Fig. 3). The molecular structures of the corresponding intermediates and transition states are displayed in Fig. 4. The pre-reaction complex IR0 has a negative Gibbs energy meaning that the reagents are weakly linked together by van der Waals interactions and hydrogen bonds. The initial step (TS1-2) corresponds to the nucleophilic attack of aniline onto the carbonate group of PC $(1.64 \AA)$ with a concerted exchange of protons from aniline towards the $\mathrm{N}$ atom of TBD $(1.41 \AA)$ and from TBD to the $\mathrm{O}$ atom of the carbonyl (1.67 ̊) (Fig. 4). This concerted transfer of protons is possible because of the two nitrogen available sites on the structure of TBD. The intermediate IR1-2 is a cyclic amino alcohol interacting with TBD by two $\mathrm{H}$-bonds. However, the structure of this intermediate is unfavourable for the ring-opening step. Thus, a rotation of TBD creating a hydrogen bond with the adjacent $\mathrm{O}$ atom of the alcohol group leads to IR3 which has a similar Gibbs energy. In the final step, TS3 corresponds to the $\mathrm{C}-\mathrm{O}$ bond cleavage and the simultaneous dual protons transfer between TBD and the adjacent $\mathrm{O}$ atom of the carbonate and between the aminoalcohol and TBD. Finally, TBD is regenerated and the phenyl $S$-hydroxyurethane is the resulting product. The formation of

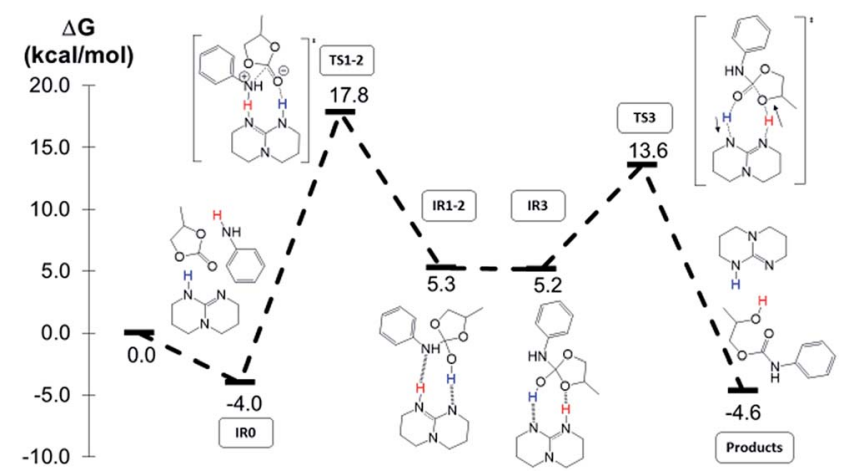

Fig. 3 Free energy profiles (M06-2X/6-311G(d,p)) and Lewis structures for the aminolysis of propylene carbonate by aniline catalysed by TBD. 


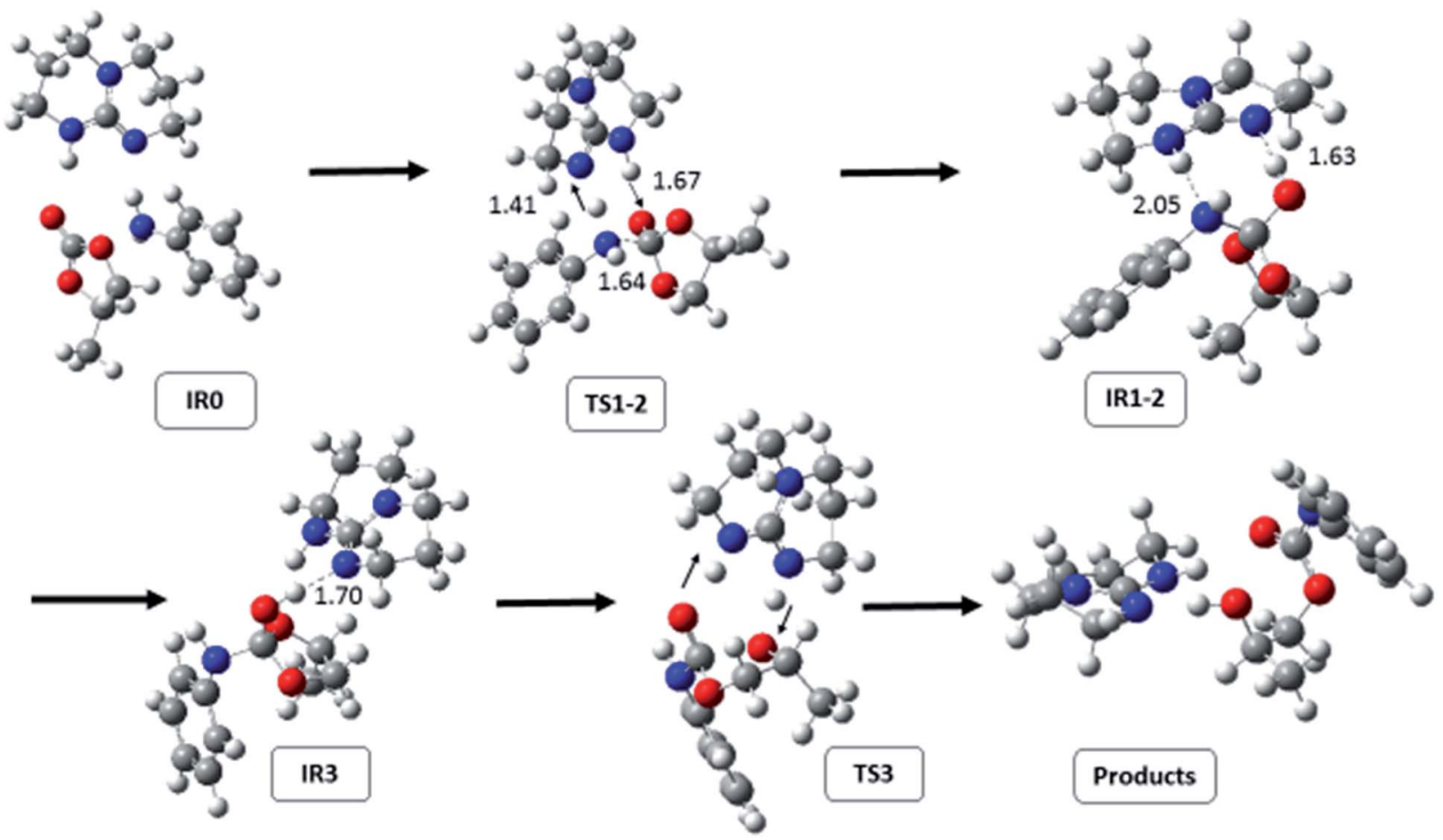

Fig. 4 Optimized geometries of the structures $(\mathrm{M06}-2 \mathrm{X} / 6-311 \mathrm{G}(\mathrm{d}, \mathrm{p}))$ of the propylene carbonate/aniline coupling in the presence of TBD as catalyst. The dashed lines depict hydrogen bond interactions, the arrows represent the concerted proton transfer and intermolecular distances are given in angstrom.

first reactive intermediate IR1-2 is the rate determining step of the reaction as it displays the highest energy transition state of the process. TBD acts as proton donor and acceptor and consequently decreases the Gibbs energy of the reaction between PC and aniline from $\Delta G=50.9 \mathrm{kcal} \mathrm{mol}^{-1}$ to $\Delta G=17.8$ $\mathrm{kcal} \mathrm{mol}^{-1}$. The proton shuttle activation mechanism pathway of TBD is consistent with the previous study of Kleij et al. ${ }^{22}$ although their reaction pathway involves a larger number of intermediates and formation of an ion pair association composed of $\mathrm{TBDH}^{+}$and an alkoxide.

To highlight the importance of the dual proton exchange on the catalytic activity of $\mathrm{TBD}$, the $\mathrm{NH}$ proton of $\mathrm{TBD}$ was substituted by a methyl substituent and the mechanism of the MTBD catalysed aminolysis of PC by aniline was investigated (Fig. 5). The activation mechanism is different as it answers a three elementary steps pathway. The molecular structures of the corresponding intermediates and transition states are displayed in Fig. 6. To improve the visualization of the systems, MTBD was represented using the stick model. The pre-reaction complex (IR0) has a positive Gibbs energy of $1.6 \mathrm{kcal} \mathrm{mol}^{-1}$. The first elementary step corresponds to the nucleophilic attack of aniline onto the $\mathrm{C}$ atom of the carbonate group of PC (TS1) resulting in an increase of the electron density on this atom. The electron density excess is then distributed between adjacent $\mathrm{O}$ atoms of the ring. The instable zwitterionic first intermediate IR1, i.e. an ammonium alkoxide, interacts with MTBD by formation of $\mathrm{H}$-bonds. The proton of the ammonium is then transferred to the nitrogen atom of MTBD (TS2) with a low activation energy barrier $\left(0.2 \mathrm{kcal} \mathrm{mol}^{-1}\right)$ relatively to the calculation error leading to an ion-pair composed of $\mathrm{MTBDH}^{+}$ and an alkoxide (IR2). To reach a lower Gibbs energy and favour the last step, IR2 undergoes a rearrangement where the proton of $\mathrm{MTBDH}^{+}$interacts with the $\mathrm{O}$ atom adjacent of the carbonyl of the carbonate group (IR3). Finally, the concerted transfer of the same proton from MTBD to the adjacent $\mathrm{O}$ atom of the carbonyl and the ring-opening of the five-membered ring (TS3) lead to the synthesis of the $S$-hydroxyurethane derivative and the regeneration of MTBD. The rate determining step is the addition of the aniline onto PC that represents the highest energy transition state of the process. The MTBD catalyst drastically decreases the Gibbs energy of the aminolysis of PC by

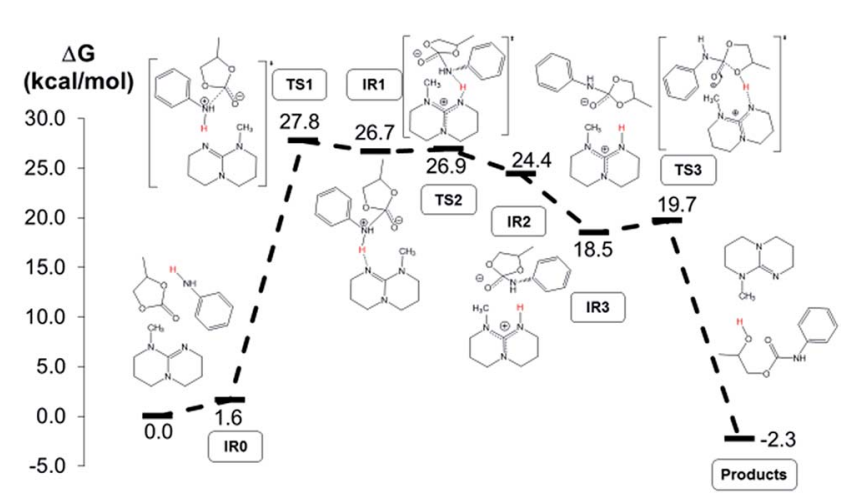

Fig. 5 Free energy profiles (M06-2X/6-311G(d,p)) and Lewis structures for the aminolysis of propylene carbonate by aniline catalysed by MTBD. 

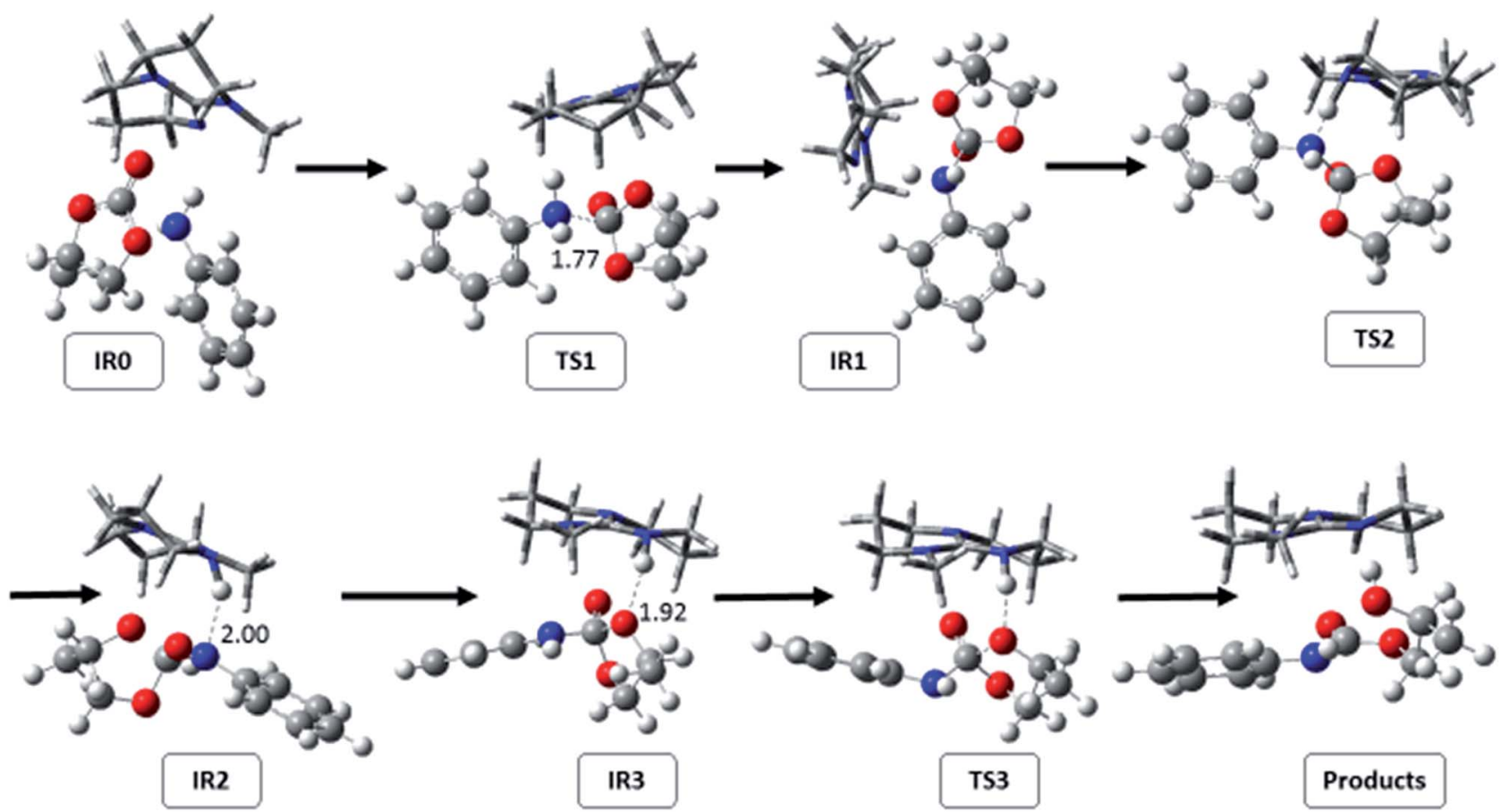

Fig. 6 Optimized geometries of the structures $(\mathrm{M} 06-2 \mathrm{X} / 6-311 \mathrm{G}(\mathrm{d}, \mathrm{p}))$ of the propylene carbonate/aniline coupling in the presence of MTBD as catalyst. The dashed lines depict hydrogen bond interactions, intermolecular distances are given in angstrom.

aniline from $\Delta G=50.9 \mathrm{kcal} \mathrm{mol}^{-1}$ to $\Delta G=27.8 \mathrm{kcal} \mathrm{mol}^{-1}$. However, the Gibbs energy value is higher than for the TBDpromoted reaction $\left(\Delta G=17.8 \mathrm{kcal} \mathrm{mol}{ }^{-1}\right)$ as the methyl group of MTBD prevents the concerted proton exchange to occur as it was observed for the most efficient TBD catalyst.

\subsection{Cyclic carbonate - methylamine coupling with TBD and MTBD catalyst}

In a first step, the activation mechanism of the TBD catalysed aminolysis of PC with methylamine was investigated (Fig. 7). In contrast to the analogous reaction with aniline, the reaction follows a three elementary steps pathway with methylamine and the pre-reaction complex has a positive Gibbs energy. The first

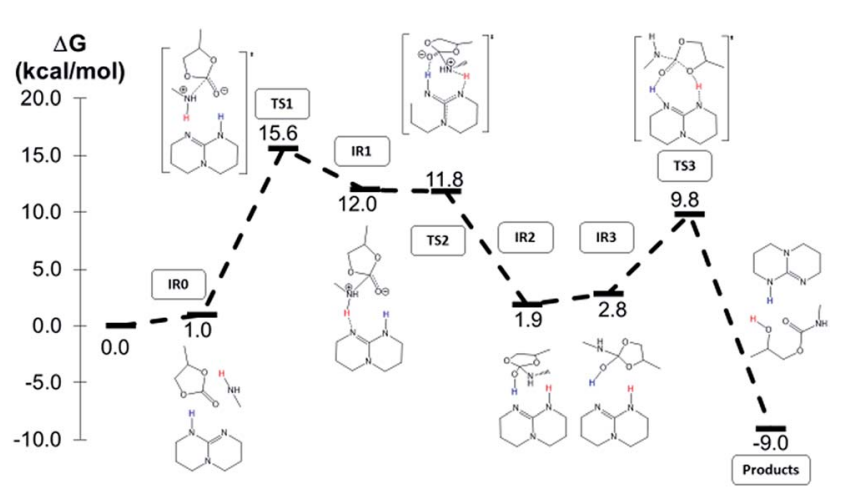

Fig. 7 Free energy profiles (M06-2X/6-311G(d,p)) and Lewis structures for the aminolysis of propylene carbonate by methylamine catalysed by TBD. transition state (TS1) corresponds to the nucleophilic attack of the amine onto the $\mathrm{C}$ atom of the carbonate of PC (Fig. 8). The distance between the amine and the $\mathrm{C}$ atom of the carbonyl group of PC is longer $(1.87 \AA)$ than for aniline (1.64 A, Fig. 4). As aliphatic amines are more nucleophilic than the aromatic ones, the nucleophilic attack of the cyclic carbonate by the methylamine and the concerted transfer of protons are dissociated in two independent steps. The ammonium alkoxide (IR1) is stabilized by $\mathrm{H}$-bonds formation between the $\mathrm{N}$ atom of TBD and the proton of the ammonium (1.61 $\AA$ ) and between the $\mathrm{O}$ atom of the carbonyl group of PC and the proton of TBD (1.74 $\AA)$. The concerted transfer of both protons involved in the $\mathrm{H}$ bond occurs in a second step (TS2). It should be noted that the ammonium alkoxide (IR1) has a higher Gibbs energy than TS2. However, the IRC confirmed that the electronic energy of IR1 is lower than for TS2 but the thermal and entropic contributions reversed the trend. The amino alcohol (IR2) which is in interaction with TBD rotates (IR3) to create a $\mathrm{H}$-bond between the proton of TBD and the adjacent $\mathrm{O}$ atom of the alcohol group (1.92 ̊). However, this rotation increases the H-bond distances implying a rise of the Gibbs energy but favours the second concerted protons transfer between TBD and the amino alcohol (TS3) leading to the $S$-hydroxyurethane and regenerating TBD. The addition of methylamine onto the cyclic carbonate is the rate determining step $\left(\Delta G=15.6 \mathrm{kcal} \mathrm{mol}^{-1}\right)$. TBD acts as a proton-relay with concerted protons transfers. As already observed with aniline, $\mathrm{TBDH}^{+}$was not identified as an intermediate for the aminolysis of PC by methylamine in contrary to the mechanism suggested by Kleij et al. with butylamine. ${ }^{22}$ However, the amino alcohol intermediate was also reported by 


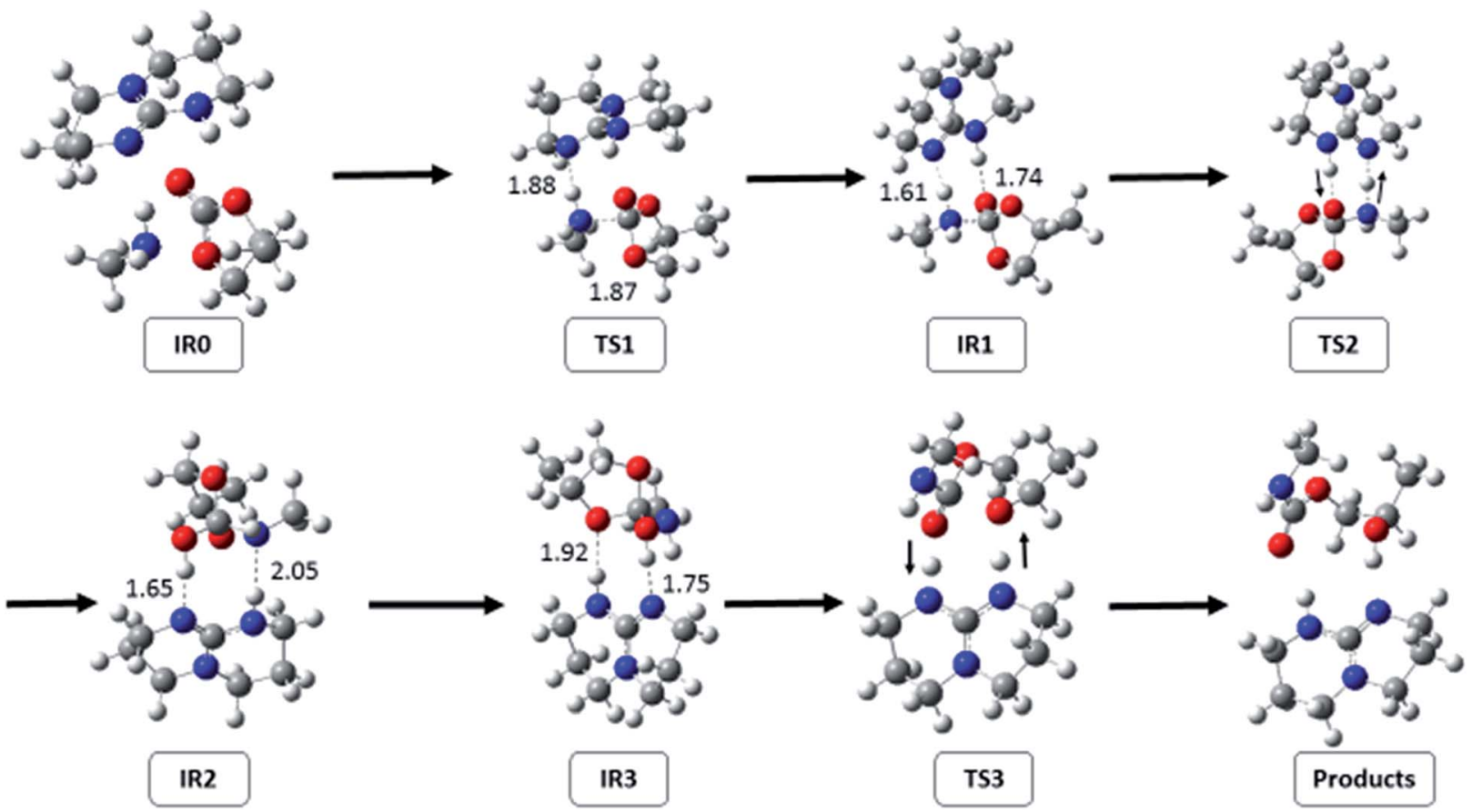

Fig. 8 Optimized geometries of the structures (M06-2X/6-311G(d,p)) of the propylene carbonate/methylamine coupling in the presence of TBD as catalyst. The dashed lines depict hydrogen bond interactions, the arrows represent the concerted proton transfer and intermolecular distances are given in angstrom.

Tiger et al. using acetic acid as bifunctional catalyst for the mechanism involving one amine molecule although two steps of the mechanism differed. ${ }^{37}$

For sake of comparison, the influence of the methyl group of MTBD on the catalyst activity for the propylene carbonate/ methylamine coupling was investigated. The MTBD catalysed synthesis of 2-hydroxypropyl methylcarbamate follows a threestep pathway, similarly to the one previously reported with aniline (Fig. 9). The pre-reaction complex composed of methylamine/MTBD/PC has a positive Gibbs free energy $(1.8 \mathrm{kcal}$ $\mathrm{mol}^{-1}$ ). The first transition state (TS1) corresponds to nucleophilic attack of the amine onto the $\mathrm{C}$ atom of the carbonate of $\mathrm{PC}$ (1.86 Å) (Fig. 10). The instable ammonium alkoxide (IR1) transfers the proton of the amine to MTBD (TS2). The resulting ion

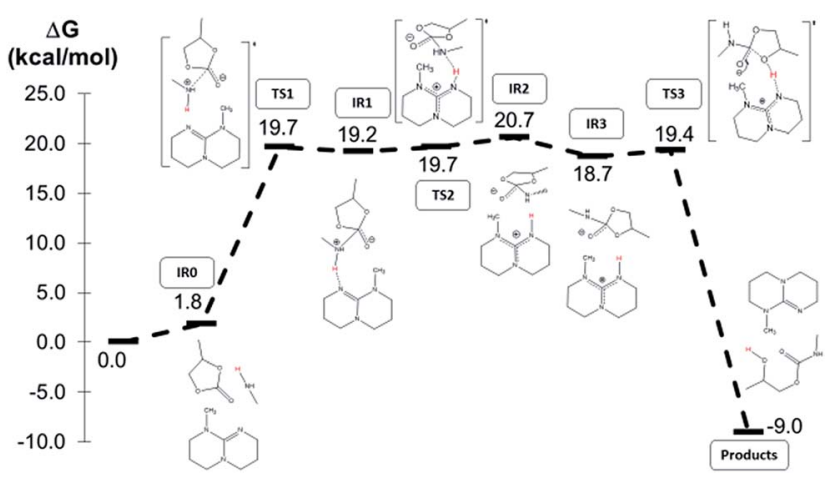

Fig. 9 Free energy profiles (M06-2X/6-311G(d,p)) and Lewis structures for the aminolysis of propylene carbonate by methylamine catalysed by MTBD. pair association [MTBDH ${ }^{+}$-alkoxide] (IR2) has a higher Gibbs energy than TS2 (we checked that the electronic energy of IR2 is lower than that of TS2 and this seldom behaviour is due to the fact that the zero-point vibrational energy (ZPE) as well as the thermal and entropic contributions to the Gibbs energy is higher for IR2 than TS2). After the rotation of $\mathrm{MTBDH}^{+}$, the Gibbs energy is decreased by $2 \mathrm{kcal} \mathrm{mol}^{-1}$ (IR3) while $\mathrm{MTBDH}^{+}$interacts with the adjacent $\mathrm{O}$ atom rather than the alkoxide. Finally, the concerted proton transfer and the ring-opening (TS3) regenerate MTBD and lead to the hydroxyurethane. The first step corresponding to the nucleophilic attack of the amine onto the carbonate can be considered as the rate determining step $(\Delta G=$ $19.7 \mathrm{kcal} \mathrm{mol}^{-1}$ ). It may be noted that the next two following steps occur with a Gibbs energy barrier lower than $1 \mathrm{kcal} \mathrm{mol}^{-1}$. The activation barrier of the aminolysis of PC by methylamine catalysed by MTBD is substantially lower compared to the one-step uncatalysed reaction $\left(\Delta G=42.6 \mathrm{kcal} \mathrm{mol}^{-1}\right)$ but still higher than for the TBD-activated pathway $\left(\Delta G=15.6 \mathrm{kcal} \mathrm{mol}^{-1}\right)$. This conclusion is in line with the one held for the aminolysis of PC by aniline catalysed by TBD and MTBD. Similarly, the methyl group of MTBD prevents both concerted protons exchanges as one nitrogen of the guanidine site is blocked. Therefore, TBD is a more efficient catalyst than MTBD for the aminolysis of propylene carbonate with alkylamines and aromatic amines.

\subsection{Cyclic carbonate - cyclohexylamine coupling with TBD catalyst}

In order to determine if the aromaticity of the benzene ring of aniline has an influence on the mechanistic pathway, the TBD 


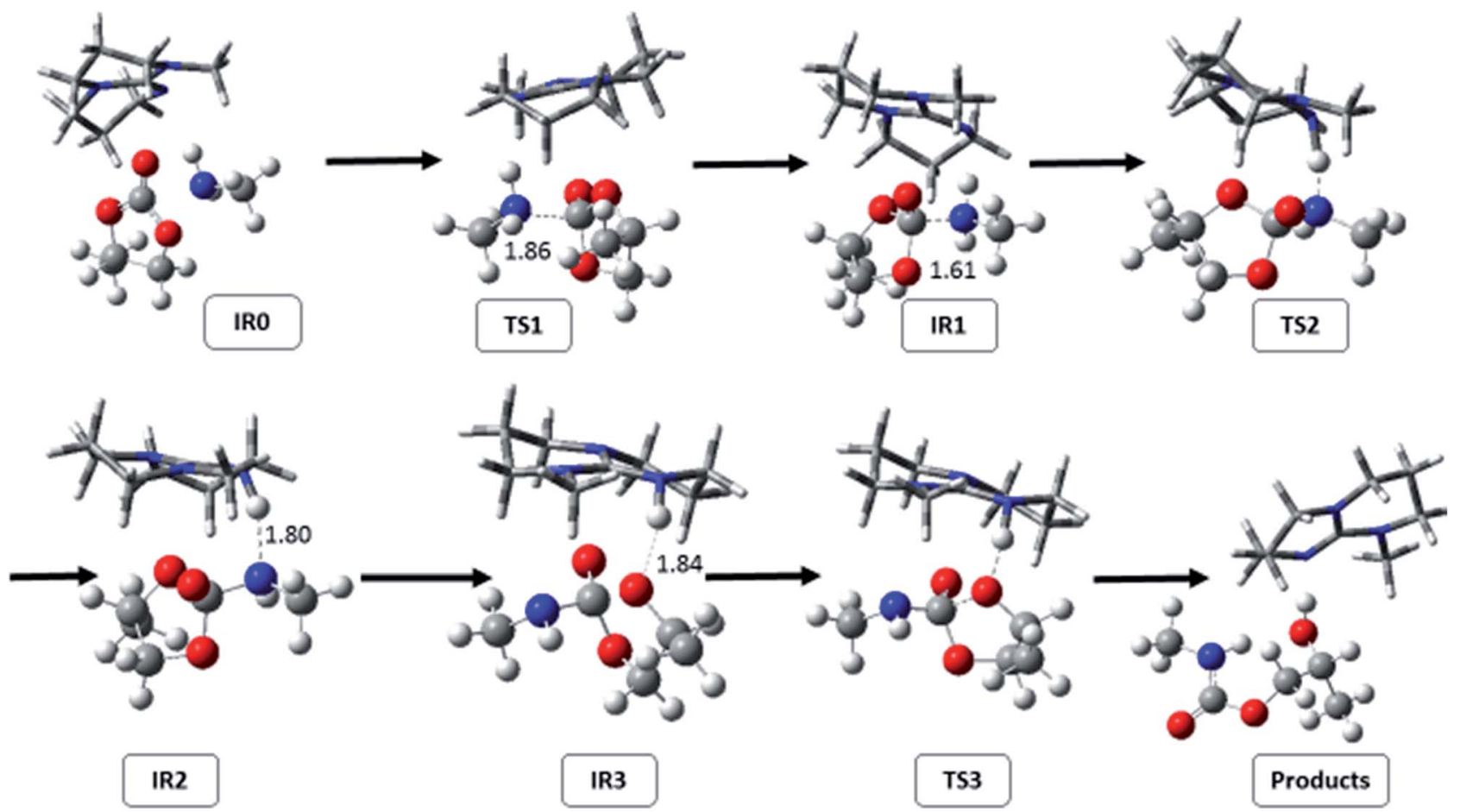

Fig. 10 Optimized geometries of the structures $(\mathrm{M} 06-2 \mathrm{X} / 6-311 \mathrm{G}(\mathrm{d}, \mathrm{p}))$ of the propylene carbonate/methylamine coupling in the presence of MTBD as catalyst. The dashed lines depict hydrogen bond interactions, intermolecular distances are given in angstrom.

catalysed aminolysis of PC was studied using cyclohexylamine. The reaction answers a three-step pathway depicted on Fig. 11. As previously reported for methylamine, the nucleophilic attack of cyclohexylamine onto PC is an independent elementary step (TS1). Indeed, the distance between the $\mathrm{N}$ atom of the amine and the $\mathrm{C}$ atom of the carbonate is longer $(1.80 \AA)$ than for aniline (1.64 Å, Fig. 4) (Fig. S3†). The ammonium alkoxide, IR1, is stabilized by two hydrogen bonds between TBD and the $\mathrm{O}$ atom of the carbonate $(1.74 \AA)$ and the amine group $(1.62 \AA)$. In a second step, TBD acts as donor and acceptor of those protons in interaction for the concerted protons transfer between TBD and the ammonium alkoxide (TS2). The resulting amino alcohol is stabilized by TBD (IR2) and rearranges to favour the last step

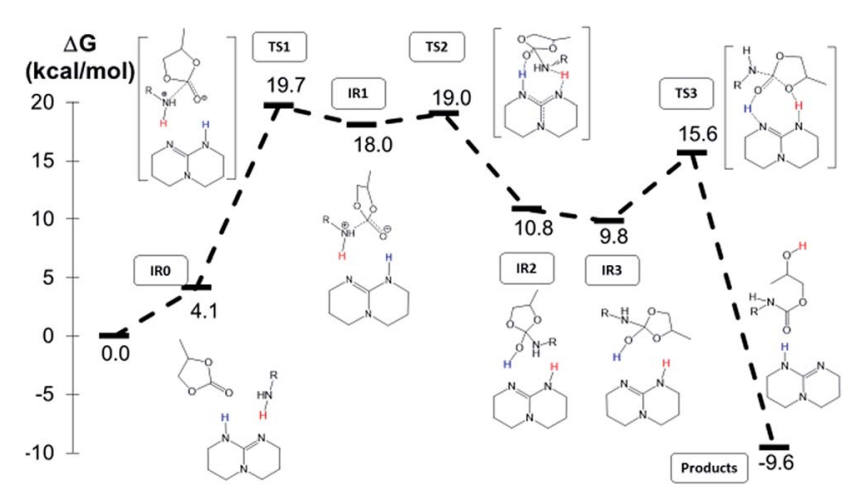

Fig. 11 Free energy profiles $(M 06-2 X / 6-311 G(d, p))$ and Lewis structures for the aminolysis of propylene carbonate by cyclohexylamine catalysed by TBD.
(IR3) by interaction between TBD and the adjacent $\mathrm{O}$ atom of the carbonate $(1.71 \AA)$. Then, the second concerted protons exchange between TBD and the amino-alcohol (TS3) allows the synthesis of the hydroxyurethane and the recovery of TBD. The nucleophilic attack of cyclohexylamine onto $\mathrm{PC}$ is the rate determining step $\left(\Delta G=19.7 \mathrm{kcal} \mathrm{mol}^{-1}\right)$. Consequently, the activation barrier is decreased when TBD is used as catalyst for the aminolysis of PC by cyclohexylamine compared to the uncatalysed reaction $\left(\Delta G=49 \mathrm{kcal} \mathrm{mol}^{-1}\right)$. The TBD-activation mechanism with cyclic alkylamines such as cyclohexylamine follows a three-step pathway like the aliphatic amines highlighting the special case of aromatic amines. The Gibbs energy for the reaction is lower for methylamine that for cyclohexylamine probably because of steric effect and the nucleophilicity. Besides, these results are consistent with experimental investigations on the aminolysis of propylene carbonate by aromatic and (cyclic) aliphatic amines. ${ }^{19,20,22}$

\section{Conclusion}

A detailed mechanistic investigation of the synthesis of hydroxyurethanes by reaction between propylene carbonate and (cyclic) alkylamines and aromatic amines has been performed. The uncatalysed reaction displays a concerted one-step mechanism. The Gibbs energy depends of the nucleophilicity of the amine and was found to evolve in the order $\Delta G$ (aniline) > $\Delta G$ (cyclohexylamine) $>\Delta G$ (methylamine). As a general trend, the guanidine-catalysed reaction answers a three-step pathway associated to the nucleophilic attack of the amine onto the 
carbonate, a proton transfer and hydrogen bonding interaction between the catalyst and the reactant, and finally a ring opening leading to the hydroxyurethane. With TBD, the two first steps, i.e. the nucleophilic attack of the amine onto the carbonate and the concerted proton transfer, occur simultaneously in the case of aniline because of its low nucleophilicity compared to methyl amine and cyclohexylamine. Besides, the activation of TBD is linked to a proton-relay mechanism with two successive concerted protons exchanges decreasing drastically the Gibbs free energy of the reaction. Such proton-relay activation is not possible in the case of MTBD hence explaining why TBD is a more efficient catalyst than MTBD as it was evidenced experimentally.

\section{Acknowledgements}

The PhD fellowship of M. ALVES was co-funded by the "IDEX (Initiative d'Excellence) program of the University of Bordeaux" and the "University of LIEGE" through the international doctoral school program "IDS-FunMat" supported by the European Community (ERASMUS MUNDUS Doctoral program). We also thank computational facilities provided by the "Pôle Modélisation" of the ISM and the MCIA (Mesocentre de Calcul Intensif Aquitain) of the University of Bordeaux (http:// www.mcia.univ-bordeaux.fr) financed by the "Conseil Regional d'Aquitaine" and the French Ministry of Research and Technology. The authors of Liège thank the "Region Wallonne" in the frame of the $\mathrm{CO}_{2}$ Green and Flycoat projects, the "Belgian Science Policy" in the frame of the "Interuniversity Attraction Poles Programme (IAP VII/5) - Functional Supramolecular Systems" and the "Fonds National pour la Recherche Scientifique” (F.R.S.-FNRS) for financial supports. C. D. is Research Director by F.R.S.-FNRS.

\section{Notes and references}

1 J. Guan, Y. Song, Y. Lin, X. Yin, M. Zuo, Y. Zhao, X. Tao and Q. Zheng, Ind. Eng. Chem. Res., 2011, 50, 6517-6527.

2 M. Bahr and R. Mulhaupt, Green Chem., 2012, 14, 483-489.

3 M. S. Kathalewar, P. B. Joshi, A. S. Sabnis and V. C. Malshe, RSC Adv., 2013, 3, 4110-4129.

4 G. Rokicki, P. G. Parzuchowski and M. Mazurek, Polym. Adv. Technol., 2015, 26, 707-761.

5 O. Kreye, H. Mutlu and M. A. R. Meier, Green Chem., 2013, 15, 1431-1455.

6 L. Maisonneuve, O. Lamarzelle, E. Rix, E. Grau and H. Cramail, Chem. Rev., 2015, 115, 12407-12439.

7 B. Grignard, J. M. Thomassin, S. Gennen, L. Poussard, L. Bonnaud, J. M. Raquez, P. Dubois, M. P. Tran, C. B. Park, C. Jerome and C. Detrembleur, Green Chem., 2016, 18, 2206-2215.

8 C. Carre, L. Bonnet and L. Averous, RSC Adv., 2014, 4, 5401854025.

9 J. Nanclares, Z. S. Petrovic, I. Javni, M. Ionescu and F. Jaramillo, J. Appl. Polym. Sci., 2015, 132, 1.

10 L. Poussard, J. Mariage, B. Grignard, C. Detrembleur, C. Jéroîme, C. Calberg, B. Heinrichs, J. De Winter,
P. Gerbaux, J. M. Raquez, L. Bonnaud and P. Dubois, Macromolecules, 2016, 49, 2162-2171.

11 A. Cornille, S. Dworakowska, D. Bogdal, B. Boutevin and S. Caillol, Eur. Polym. J., 2015, 66, 129-138.

12 E. K. Leitsch, G. Beniah, K. Liu, T. Lan, W. H. Heath, K. A. Scheidt and J. M. Torkelson, ACS Macro Lett., 2016, 5, 424-429.

13 C. Maeda, Y. Miyazaki and T. Ema, Catal. Sci. Technol., 2014, 4, 1482.

14 G. Fiorani, W. Guo and A. W. Kleij, Green Chem., 2015, 17, 1375-1389.

15 M. Alves, B. Grignard, S. Gennen, R. Mereau, C. Detrembleur, C. Jerome and T. Tassaing, Catal. Sci. Technol., 2015, 5, 4636-4643.

16 S. Gennen, M. Alves, R. Méreau, T. Tassaing, B. Gilbert, C. Detrembleur, C. Jerome and B. Grignard, ChemSusChem, 2015, 8, 1845-1849.

17 S. Foltran, J. Alsarraf, F. Robert, Y. Landais, E. Cloutet, H. Cramail and T. Tassaing, Catal. Sci. Technol., 2013, 3, 1046-1055.

18 S. Foltran, R. Mereau and T. Tassaing, Catal. Sci. Technol., 2014, 4, 1585-1597.

19 R. H. Lambeth and T. J. Henderson, Polymer, 2013, 54, 55685573.

20 M. Blain, L. Jean-Gerard, R. Auvergne, D. Benazet, S. Caillol and B. Andrioletti, Green Chem., 2014, 16, 4286-4291.

21 F. Camara, S. Benyahya, V. Besse, G. Boutevin, R. Auvergne, B. Boutevin and S. Caillol, Eur. Polym. J., 2014, 55, 17-26.

22 W. Guo, J. Gõnzalez-Fabra, N. A. G. Bandeira, C. Bo and A. W. Kleij, Angew. Chem., Int. Ed., 2015, 54, 11686-11690.

23 M. Fleischer, H. Blattmann and R. Mulhaupt, Green Chem., 2013, 15, 934-942.

24 L. Maisonneuve, A. S. More, S. Foltran, C. Alfos, F. Robert, Y. Landais, T. Tassaing, E. Grau and H. Cramail, RSC Adv., 2014, 4, 25795-25803.

25 V. M. Lombardo, E. A. Dhulst, E. K. Leitsch, N. Wilmot, W. H. Heath, A. P. Gies, M. D. Miller, J. M. Torkelson and K. A. Scheidt, Eur. J. Org. Chem., 2015, 2015, 2791-2795.

26 Q. Chen, K. Gao, C. Peng, H. Xie, Z. K. Zhao and M. Bao, Green Chem., 2015, 17, 4546-4551.

27 V. Besse, F. Camara, F. Méchin, E. Fleury, S. Caillol, J.-P. Pascault and B. Boutevin, Eur. Polym. J., 2015, 71, 1-11.

28 M. K. Kiesewetter, M. D. Scholten, N. Kirn, R. L. Weber, J. L. Hedrick and R. M. Waymouth, J. Org. Chem., 2009, 74, 9490-9496.

29 L. Simón and J. M. Goodman, J. Org. Chem., 2007, 72, 9656-9662. 30 I. Nifant'ev, A. Shlyakhtin, V. Bagrov, B. Lozhkin, G. Zakirova, P. Ivchenko and O. Legon'kova, React. Kinet., Mech. Catal., 2016, 117, 447-476.

31 A. Chuma, H. W. Horn, W. C. Swope, R. C. Pratt, L. Zhang, B. G. G. Lohmeijer, C. G. Wade, R. M. Waymouth, J. L. Hedrick and J. E. Rice, J. Am. Chem. Soc., 2008, 130, 6749-6754.

32 P. Hammar, C. Ghobril, C. Antheaume, A. Wagner, R. Baati and F. Himo, J. Org. Chem., 2010, 75, 4728-4736.

33 J. Ma, X. Zhang, N. Zhao, F. Xiao, W. Wei and Y. Sun, J. Mol. Struct.: THEOCHEM, 2009, 911, 40-45. 
34 M. A. Levina, V. G. Krasheninnikov, M. V. Zabalov and R. P. Tiger, Polym. Sci., Ser. B, 2014, 56, 139-147.

35 M. V. Zabalov, R. P. Tiger and A. A. Berlin, Dokl. Chem., 2011, 441, 355-360.

36 M. V. Zabalov, R. P. Tiger and A. A. Berlin, Russ. Chem. Bull., 2012, 61, 518-527.

37 M. V. Zabalov, M. A. Levina, V. G. Krasheninnikov and R. P. Tiger, Russ. Chem. Bull., 2014, 63, 1740-1752.

38 M. J. S. Dewar, E. G. Zoebisch, E. F. Healy and J. J. P. Stewart, J. Am. Chem. Soc., 1985, 107, 3902-3909.
39 J. Řezáč and P. Hobza, J. Chem. Theory Comput., 2012, 8, 141151.

40 AMPAC 10, (C) 1992-2013 Semichem, Inc. PO Box 1649, Shawnee, KS 66222.

41 D. A. Liotard, Int. J. Quantum Chem., 1992, 44, 723-741.

42 M. J. Frisch and A. D. Becke, Gaussian 09, Revision A.02, 2009, vol. 98, pp. 5648-5652.

43 Y. Zhao and D. G. Truhlar, Theor. Chem. Acc., 2008, 120, 215241. 